\title{
Incidence of peripheral vascular disease in women: Is it different from that in men?
}

\author{
Vasana Cheanvechai, MD, ${ }^{a}$ Nancy L. Harthun, MD, ${ }^{\mathrm{b}}$ Linda M. Graham, MD, ${ }^{\mathrm{c}}$ Julie A. Freischlag, MD, ${ }^{\mathrm{d}}$ and \\ Vivian Gahtan, MD
}

\begin{abstract}
Editorial Note: The gender initiative continues with editorials addressing noncardiac vascular surgery: (1) Experts discuss sex-based differences in the prevalence of vascular disease; (2) the pathophysiology, risks, and benefits of surgical treatment of carotid disease in women; (3) the need for clarifying optimal timing for surgical repair of abdominal aortic aneurysms in women and for refining endovascular repair technology for small patients; and (4) current outcomes (limb salvage, graft patency, and mortality) and future research in women with peripheral arterial occlusive disease. The series continues next month with editorials on end-stage heart failure.
\end{abstract}

Nancy A. Nussmeier, MD Texas Heart Institute

See related editorials on pages 318,322 , and 325 .

\footnotetext{
From the Division of Vascular Surgery, University of Maryland, Baltimore, Md; the Division of TCV Surgery, ${ }^{\mathrm{b}}$ University of Virginia Health System, Charlottesville, Va; the Department of Vascular Surgery, ${ }^{c}$ the Cleveland Clinic Foundation, Cleveland, Ohio; the Department of Surgery, ${ }^{\mathrm{d}}$ Johns Hopkins School of Medicine, Baltimore, Md; and the Section of Vascular Surgery, ${ }^{\mathrm{e}}$ Yale University School of Medicine, New Haven, Conn.

This is a project of the Society of Vascular Surgery, Committee on Women's Issues.
}

Supported in part by National Institutes of Health K12 HD043489 Building Interdisciplinary Research Careers in Women's Health.

Received for publication Sept 29, 2003; accepted for publication Oct 6, 2003.

Address for reprints: Vivian Gahtan, MD, SUNY Upstate Medical University College of Medicine, Department of Surgery, 750 East Adams St, Syracuse, NY 13210 (Email: gahtanv@upstate.edu).

J Thorac Cardiovasc Surg 2004;127:314-7

$0022-5223 / \$ 30.00$

Copyright ( $\odot 2004$ by The American Association for Thoracic Surgery

doi:10.1016/j.jtcvs.2003.10.019

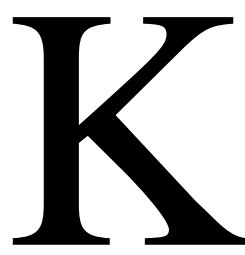

nowledge of the clinical consequences of atherosclerosis and cardiovascular disease has grown tremendously over the years. Most persons, patients and physicians alike, understand and accept the critical importance of heart disease, yet the significance of noncardiac vascular disease remains largely underappreciated. The 3 major areas of noncardiac vascular disease include carotid artery occlusive disease, aortic aneurysmal disease, and peripheral arterial occlusive disease (PAD). These diseases, with their associated risks of stroke, limb loss, and death, are often undiagnosed and untreated despite being common causes of death and loss of function in the United States. Although previous studies have reported that the prevalence of vascular disease is greater in men than in women, that gap closes quickly with increasing age. As the American population ages, the prevalence of noncardiac vascular disease in women will increase, making it a leading cause of mortality and morbidity for women. The importance of disease prevention and detection of noncardiac vascular disease in women cannot be overlooked. To date, few studies have focused on the prevalence and importance of vascular disease in women.

\section{Carotid Artery Occlusive Disease}

Stroke is the third leading cause of death in the United States and a leading cause of permanent disability among older Americans. Nearly $\$ 70$ billion is estimated to be spent each year on the care of stroke survivors. ${ }^{1}$ Most strokes are ischemic, and most ischemic strokes are caused by cerebrovascular disease. According to the Atherosclerosis Risk in Communities Study from the American Heart Association, approximately $83 \%$ of strokes are ischemic (thromboembolic), whereas $17 \%$ are hemorrhagic. The risk of stroke is reported to be 1.5 times greater in men than in women of the same age. The natural history of the patients experiencing a stroke suggests that only $50 \%$ will be alive at 5 years, with $38 \%$ dying from the initial stroke. Of those who survive the initial event, only $30 \%$ will function normally, and up to $5 \%$ will require custodial care. Any patient with symptoms of cerebrovascular disease should be managed aggressively because the sequelae of a stroke can be devastating. However, only $30 \%$ to $50 \%$ of patients have any symptoms before a stroke, and therefore the importance of detecting cerebral vascular disease cannot be overemphasized.

The benefit of carotid endarterectomy for both symptomatic and asymptomatic carotid artery stenosis has been well studied. However, those studies that examined the role of carotid endarterectomy for occlusive disease included a low percentage of women. ${ }^{2,3}$ Men comprise the majority of patients recruited for the major clinical trials on asymptomatic and symptomatic carotid disease. (Asymptomatic Carotid Atherosclerosis Study: 67\% were men, and 33\% were women; North American Symptomatic Carotid Endarterectomy Trial: $71 \%$ were men, and 30\% were women; the Veterans Affairs cooperative study enrolled no women) ${ }^{4-7}$ A study that specifically reviewed the sex differences in carotid endarterectomy outcomes from Ontario, Canada, reported that only 35\% of the 6038 patients in their registry were women. ${ }^{8}$ Consequently, conclusions have been drawn on the potential benefits of carotid surgery for women. These studies, however, might not necessarily reflect the 
true incidence of the disease in women, and a clear understanding of cerebrovascular disease in women is clouded by a scarcity of studies with an adequate number of women.

\section{Aortic Aneurysmal Disease}

Abdominal aortic aneurysms (AAAs) account for at least 15,000 deaths per year in the United States. This figure might even be a gross underestimate because many patients with ruptured aneurysms are not given a diagnosis before their rupture, and furthermore, a number of these patients might not even make it to the hospital. ${ }^{9,10}$ Most surgical series suggest that AAAs are primarily a disease of elderly men, with the number of affected men outnumbering women. ${ }^{11-13}$ Age-adjusted incidence for both asymptomatic and ruptured AAAs is 4 to 6 times higher in men compared with that in women. ${ }^{14,15}$ This risk of AAA increases with age, and the difference in prevalence between men and women closes in the eighth decade of life.

Although most patients with AAAs are asymptomatic and often are given a diagnosis during routine physical examination or evaluation for other disease processes, the mortality rate for those symptomatic can be as high as $90 \%$. Rupture from AAA constitutes the 10th leading cause of death among men older than 55 years of age. When aneurysms are diagnosed early, they can be treated safely, with a mortality rate of 5\% or less. ${ }^{16-19}$ Currently, many AAAs can be treated by using less-invasive techniques that avoid the need for major surgical procedures. However, when AAAs progress to rupture, they are fatal in more than half the cases. AAAs can be diagnosed easily in minutes without risk or discomfort by using duplex ultrasound scanning. ${ }^{20-22}$ AAA and its pathogenesis remain a central concern in the study of vascular disease because of the incidence and catastrophic consequences of rupture.

As the population ages and the gap in prevalence of AAAs between men and women narrows, it will become increasingly important to determine specific risks that might affect women. Women are often given a diagnosis at a later age and are offered elective repair at a significantly lower rate than men. ${ }^{23,24}$ In addition, AAAs diagnosed in women are more likely to be ruptured at the time of diagnosis than is the case among men. ${ }^{25}$ Women also are less likely candidates for current less-invasive techniques of repair, often because of anatomic limitations. Perhaps sex differences in outcomes of diagnostic and therapeutic procedures influence physicians' patterns in referring women for treatment.

\section{Peripheral Arterial Occlusive Disease}

PAD affects 8 to 12 million Americans. The estimate is that nearly $20 \%$ of persons older than 70 years of age have PAD. PAD is associated with a 5-fold to 6-fold increased risk of cardiovascular morbidity and death. ${ }^{26,27}$ Intermittent clau- dication is the classic manifestation and is associated with impaired lifestyle and lower extremity functioning. Patients also might have limb-threatening ischemia. The ankle-brachial index (ratio of the systolic blood pressure in the ankle to that in the arm) is a reliable, simple, and objective measurement used to assess PAD. ${ }^{28-30}$ Many patients are not given a diagnosis of PAD until they have symptoms of intermittent claudication. ${ }^{31}$ It has been well documented that development of mild-to-moderate intermittent claudication poses a low threat of limb loss, with up to $75 \%$ of patients stabilizing or improving, whereas only $5 \%$ to $7 \%$ eventually require amputation. The effect of amputation can be devastating, with an overall survival rate of $50 \%$ or less at 10 years compared with $90 \%$ at 5 years in age-adjusted control subjects. Many patients with claudication, however, do not complain of symptoms and often accept difficulty in walking as part of the normal aging process.

Previous studies have shown that women are less likely to be given a diagnosis on the basis of symptoms but do have clinically significant PAD when tested. ${ }^{32,33}$ The traditional belief that the prevalence of PAD is greater in men than in women does not take into account that women might have more asymptomatic disease. Symptomatic PAD so predominates in men that many reports of surgical therapy do not investigate sex-specific outcomes. ${ }^{34}$ Moreover, studies have shown that infrainguinal arterial reconstructions performed on women tend to be for more advanced disease compared with those in their male counterparts, and the women tend to be older. ${ }^{35,36}$ In addition, experience at the University of Maryland over the past 5 years disclosed that more than $50 \%$ of women who have PAD are seen initially with such advanced limb-threatening ischemia that they undergo primary amputation without the opportunity for revascularization (unpublished data). We speculate that some of the reasons women might be given diagnoses at a more advanced stage of ischemia are (1) that women might focus more on seeking medical care for their families than for themselves, (2) that women are more likely to ignore mild-to-moderate symptoms (attributing symptoms to "old age") and therefore present with more advanced occlusive disease, and (3) economic considerations. Without correcting for the more advanced presentation, women might appear to have worse outcomes as a group.

\section{The American Vascular Association National Screening Program}

Accurate incidence estimates for carotid artery disease, peripheral arterial disease, and aneurysmal disease have not been available because nationwide screening surveys of the population were not conducted until 2002. The American Vascular Association (AVA) then performed its first National Screening Program for carotid disease, AAA, and PAD in older Americans at high risk for atherosclerosis. In its first year, more than 850 persons were tested at 17 
centers across the nation. The mean patient age was 65 years. More than $60 \%$ of those who presented for screening were women, and more than $13 \%$ of those tested had abnormal examinations. This screening was expanded to 48 centers in 2003, during which a total of 1587 persons were screened. Again more than $60 \%$ of those screened were women. The mean patient age was 68 years. These 2 screenings combined totaled 2446 persons (1479 women and 967 men).

Through the AVA screening, carotid artery stenosis (internal carotid artery stenosis $>50 \%$ ) was observed in approximately $8 \%$ of the population screened. An additional $2 \%$ were found to have severe carotid artery disease $(80 \%$ $99 \%$ ). Thus clinically relevant carotid artery disease was found in approximately $9 \%$ of the persons screened. Overall, carotid artery stenosis was significantly more likely in men $(8 \%)$ than in women $(6 \%, P=.03)$. Less than half $(47 \%)$ of the persons determined to have more than $50 \%$ internal carotid artery stenosis were receiving antiplatelet medications (aspirin, clopidogrel, or ticlopidine) that might reduce their risk of stroke. Among those with $80 \%$ to $99 \%$ internal carotid artery stenosis, nearly one third (29\%) were not receiving antiplatelet treatment. Interestingly, of those patients with carotid artery stenosis, men were more likely than women to be taking antiplatelet medications $(58 \%$ vs $32 \%, P=.0006)$.

AAAs (aortic diameter $>3.0 \mathrm{~cm}$ ) were observed in $2 \%$ of the population screened; approximately $11 \%$ were more than $5.0 \mathrm{~cm}$ in diameter, and none of these had been diagnosed previously. Of the total persons in both screenings combined with an aorta of greater than $3.0 \mathrm{~cm}, 2 \%$ were women, and $4 \%$ were men. Although more AAAs were detected in men than in women during this screening, the ratio of men to women was not as disparate as traditionally reported.

PAD (ankle-brachial index <0.85) was observed in 9\% of the population screened, $11 \%$ of men and $8 \%$ of women $(P=.001)$. Among those observed to have PAD at the time of screening, less than half $(47 \%)$ were not receiving medical treatments (eg, antiplatelet or lipid-lowering agents) that might reduce the risk of myocardial infarction and stroke (known incidence to be 2-3 times more common in those with PAD). As with carotid disease, men were more likely to be taking antiplatelet medications than women (58\% vs $40 \%, P=.0067)$. Moreover, men were more likely $(87 \%)$ than women $(63 \%)$ to be receiving lipid-lowering medications $(P=.0062)$.

Overall, this national screening program confirms that vascular disease is underdiagnosed and undertreated in a broad segment of the US population. Similarly, a regional screening program of 8476 persons in New England reported a high prevalence (37\%) of previously undiagnosed peripheral vascular disease. Peripheral vascular disease was identified on the basis of either an ankle-brachial index of less than 0.90 , carotid artery stenosis of more than $15 \%$, or AAA of greater than $3 \mathrm{~cm}$ in the population tested. As in the AVA national screening program, $67 \%$ of the population screened were women with a mean age of 65 years. ${ }^{37}$ These screenings showed that although men were more likely to have carotid artery stenosis, PAD, and aneurysmal disease, the ratios are not as disparate as touted previously. Over the next 5 years, this annual AVA screening program will continue to expand, with a goal of greater than 5000 patients screened. The data collected will become the most comprehensive collection of information regarding the prevalence of vascular disease assembled.

\section{References}

1. American Heart Association. Heart disease and stroke statistics-2003 update. Dallas, Tex: American Heart Association; 2002.

2. Mattos MA, Sumner DS, Bohannon WT, et al. Carotid endarterectomy in women: challenging the results from ACAS and NASCET. Ann Surg. 2001;234(4):438-46.

3. Barnett HJM, Taylor DW, Eliasziw M, et al. Benefit of carotid endarterectomy in patients with symptomatic moderate or severe stenosis. N Engl J Med. 1998;339(20):1415-25.

4. Executive Committee for the Asymptomatic Carotid Atherosclerosis Study. Endarterectomy for asymptomatic carotid artery stenosis. JAMA. 1995;273:1421-8.

5. Ferhuson CG, Eliasziw M, Barr HW, et al. The North American Symptomatic Carotid Endarterectomy Trial. Surgical results in 1415 patients. Stroke. 1999;40:1751-8.

6. North American Symptomatic Carotid Endarterectomy Trial Collaborators. Beneficial effect of carotid endarterectomy in symptomatic patients with high-grade stenosis. N Engl J Med. 1991;325:445-53.

7. Hobson RW II, Weiss DG, Fields WF, et al. Efficacy of carotid endarterectomy for asymptomatic carotid stenosis. $N$ Engl J Med. 1993;328:221-7.

8. Kapral MK, Wang H, Austin PC, et al. Sex differences in carotid endarterectomy outcomes: results from the Ontario Carotid Endarterectomy Registry. Stroke. 2003;34(5):1120-5.

9. Bengtsson H, Nilsson P, Bergqvist D. Natural history of abdominal aortic aneurysm detected by screening. Br J Surg. 1993;80(6):718-20.

10. Bengtsson $\mathrm{H}$, Bergqvist $\mathrm{D}$. Ruptured abdominal aortic aneurysm: a population based study. J Vasc Surg. 1993;18(1):74-80.

11. Chosky SA, Wilmink ABM, Quick CRG. Ruptured abdominal aortic aneurysm in the Huntingdon district: a 10-year experience. Ann R Coll Surg Engl. 1999;81:27-31.

12. Melton LF, Bickerstaff LK, Hollier LH, et al. Changing incidence of abdominal aortic aneurysms: a population-based study. Am J Epidemiol. 1984;120:379-86.

13. Powell JT, Greenlalgh RM. Multifactorial inheritance of abdominal aortic aneurysm. Eur J Vasc Surg. 1987;1(1):29-31.

14. Cronenwett JL, Krupski WC, Rutherford RB. Abdominal aortic and iliac aneurysms in vascular surgery. 5th ed. Philadelphia: WB Saunders; 2000. p. 1249.

15. Vardulaki KA, Walker NM, Day NE, Duffy SW, Ashton HA, Scott RAP. Quantifying the risks of hypertension, age, sex and smoking in patients with abdominal aortic aneurysm. Br J Surg. 2000;87(2):195200.

16. Scott RAP, Wilson NM, Ashton HA, Kay DN. Influence of screening on the incidence of ruptured abdominal aortic aneurysm: 5 year results of randomized controlled study. Br J Surg. 1995;82(8):1066-70.

17. Lederle FA, Johnson GR, Wilson SE, et al. The aneurysm detection and management study screening program: validation cohort and final results. Arch Intern Med. 2000;160(10):1425-30.

18. Morris GE, Hubbard CS, Quick CR. An abdominal aortic aneurysm screening programme for all males over the age of 50 years. Eur $J$ Vasc Surg. 1994;8(2):156-60.

19. Scott RA, Ashton HA, Kay DN. Abdominal aortic aneurysm in 4237 
screened patients: prevalence, development and management over 6 years. Br J Surg. 1991;78(9):1122-5.

20. Lindholt JS, Henneberg EW, Fasting H, Juul S. Mass or high-risk screening for abdominal aortic aneurysm. Br J Surg. 1997;84(1):40-2

21. Lindholt JS. Screening for abdominal aortic aneurysm. Br J Surg. 2001;88(5):625-6.

22. Heather BP, Poskitt KR, Eranshaw JJ, Whyman M, Shaw E. Population screening reduces mortality rate from aortic aneurysm in men. Br J Surg. 2000;87(2):750-3.

23. Lederle FA, Johnson GR, Wilson SE, et al. Abdominal aortic aneurysm in women. $J$ Vasc Surg. 2001;34:122-6.

24. Katz DJ, Stanley JC, Zelenock GB. Gender differences in abdominal aortic aneurysm prevalence, treatment, and outcome. J Vasc Surg. 1997;25:561-8.

25. Darling RC III, Brewster DC, Darling RC, et al. Are familial abdominal aortic aneurysms different? J Vasc Surg. 1989;10:39-43.

26. Levy PJ. Epidemiology and pathophysiology of peripheral arterial disease. Clin Cornerstone. 2002;4(5):1-15.

27. Johnsen MC, Landow WJ, Sonnefield J, McClenny TE, Beatty PT, Raabe RD. Evaluation of Legs For Life national screening and awareness program for peripheral vascular disease: results of a follow-up survey of screening participants. $J$ Vasc Interv Radiol. 2002;13(1):2535.

28. Hirsch A, Criqui M, Treat-Jacobson D, et al. Peripheral arterial disease detection, awareness, and treatment in primary care. JAMA. 2001;286: 1317-24.

29. Carter SA. Role of pressure measurements in vascular disease. In:
Berstein EF, ed. Noninvasive diagnostic techniques in vascular disease. St Louis, Mo: CV Mosby; 1985. p. 514-44.

30. McDermott M, Mehta S, Liu K, et al. Leg symptoms, the anklebrachial index, and walking ability in patients with peripheral arterial disease. J Gen Intern Med. 1999;14:173-81.

31. Collins TC, Petersen NJ, Suarez-Almazor M, Ashton CM. The prevalence of peripheral arterial disease in a racially diverse population. Arch Intern Med. 2003;163(12):1469-74.

32. Higgins JP, Higgins JA. Epidemiology of peripheral arterial disease in women. J Epidemiol. 2003;13(1):1-14.

33. Gardner AW. Sex differences in claudication pain in subjects with peripheral arterial disease. Med Sci Sports Exerc. 2002;34(11):1695708.

34. Wenger NK, Speroff L, Packard B. Cardiovascular health and disease in women. N Engl J Med. 1993;329(4):247-56.

35. Eugster T, Gurke L, Obeid T, Stierli P. Infrainguinal arterial reconstruction: female gender as a risk factor for outcome. Eur $J$ Vasc Endovasc Surg. 2002;24(3):245-58.

36. Roddy SP, Darling RC 3rd, Maharaj D, et al. Gender-related differences in outcome: an analysis of 5880 infrainguinal arterial reconstructions. J Vasc Surg. 2003;37(2):399-402.

37. Lin JC, Estes JM, Muto PA, Iafrati MD. Routine vascular screening of peripheral vascular disease, carotid artery stenosis and abdominal aortic aneurysm of the general population in New England. Abstract presented at: 30th Annual Meeting of the New England Society for Vascular Surgery; September 2003; Newport, RI.

\section{The Journal of Thoracic and Cardiovascular Surgery Conflict of Interest Policy}

To assure fairness to authors submitting work for consideration in The Journal of Thoracic and Cardiovascular Surgery, a mechanism exists for managing conflicts of interest. The editor and each of the section editors complete a "Conflict of Interest" form that identifies any and all relationships with commercial and other academic entities. When the editor has a potential conflict because of a relationship with another entity or author, the editor appoints an alternate editor from among the section editors or editorial board members who assumes the entire responsibility for final decisions on the manuscript in question. The editor does not read the reviews that are submitted nor engage in discussing the manuscript prior to the final decision. When the conflict of interest involves a section editor, a "guest section editor" is appointed who fills the role normally played by the conflicted section editor. All members of the editorial board and reviewers are asked to indicate any conflict of interest when they agree to review a manuscript. 